\title{
Predicting Factors That Influence Students' Learning Outcomes Using Learning Analytics in Online Learning Environment
}

\author{
https://doi.org/10.3991/ijet.v16i01.16325 \\ Saida Ulfa $(\bowtie)$ \\ State University of Malang, Malang, Indonesia \\ saida.ulfa.fipeum.ac.id \\ Izzul Fatawi \\ Islamic Institute of Nurul Hakim, Lombok, Indonesia
}

\begin{abstract}
The application of online learning has increased significantly, recently. One of the key successes in online learning is student interactions. An active learning strategy would engage the students to interact with the course or to get involved in the learning process. The objective of this research was to predict which one of the student activities that would improve the learning outcome of the students? All the activities are related to non-human interaction. One of the activities is concept mapping. All the students' activities in online learning were stored in LMS and the data generated as a learning analytics. A linear regression method was used to analyze the data. This research confirmed that working on exercises by using concept mapping yields significant results in improving the learning outcome of students.
\end{abstract}

Keywords-Concept mapping, learning analytics, learning outcomes, nonhuman interaction, student success in online learning

\section{Introduction}

Nobody denies that education is changing and technology has a big part in changing the current educational landscape. In this big data era, online learning usage has increased significantly, and has become more popular during the Covid-19 outbreak, and would be expected to substitute the traditional classroom (face to face setting). Therefore, educators should provide quality learning experiences for the students.

In order to promote student success in online learning, There are several important aspects that need to be considered in organizing online learning such as the use of application software which has many advantages including the ease of administering, managing, documenting, monitoring, content delivery, and evaluating online learning [1], utilization of educational data mining to improve the quality of education [2], as well as the application of learner-centered learning strategies [3]. 
A Learning management system (LMS) is a learning platform that is used to administer the educational program in an online learning environment which adopts the learning activities of the traditional classroom. An LMS has a common component consisting of synchronous and asynchronous communication tools, management features, and assessment utilities [4]. These features make the teacher is easier to structure the course. Thus, an LMS as a learning environment that is able to support both teachers and students to conduct self-directed learning [5].

An LMS records activity data on the LMS Activity logs. It collects student interaction activities data, such as when, how long and how often they access the facilities provided such as content, quiz, forum, and other facilities. Data generated by each online student and it will be different from each other. The log data generated from an LMS is called Learning Analytics (LA) and its function is to extract data in a big volume [6].

The LA is used to optimize the learning process by solving problems that exist within the learning process. The use of data with the aim of determining the right strategy and policy is known as a data-driven approach. Many problems can be solved by utilizing a data-driven approach, as stated by Jagadish, et al [7]. The use of LA can create a more personal, adaptive and interactive learning environment in order to increase the effectiveness in teaching and learning and improve the performance of students and teachers [8].

Responding to the large volume of educational data, it is expected that LA will be important equipment in supporting the teacher to have a greater understanding of student needs and performances [9]. LA provides meaningful information to teachers by combining and analyzing students' historical data during learning and then taking action to reflect and intervene in learning to increase students' absorption and participation [10].

However, the use of LMS and LA alone are not enough without an instructional strategy in online learning. An instructional strategy is aimed at increasing activity in learning. Student activeness in online learning can be seen from student interaction. In an online learning system, it plays an important role [11]. The student interaction is produced by active learning strategies as well. An active learning strategy can promote students' engagement in order to interact with the course or to become involved in the learning process [12].

This study uses LMS and LA as infrastructure in online learning. In addition, the learning activity used is the use of the Concept Mapping (CM) strategy which is one of the eight ways to promote generative learning activities [13].

In addition to CM, reading contents, number of logins, length of login, and submitting assignments are online learning activities which are the focus of this research. According to Hirumi [14], these activities are categorized as non-human interaction. All the activities were recorded in the LMS and the data presented as a learning analytics. The purpose of this study was to predict which of these activities would affect the learning outcome. Therefore, in this study, an experiment was carried out with the test subjects being students of the Educational Technology Department, State University of Malang. The test results were analyzed using regression analysis with multiple linear regression (MLR). 


\section{$2 \quad$ Literature Review}

\subsection{Active learning strategies in online learning}

Interaction in online learning: Online learning activities combine several student's interaction types during the learning process. Many researches have discussed student interaction due to its important role in online learning. Hirumi [14] has summarized several types of interactions in online learning which consists of three levels, namely student self-interaction which relates to cognitive processes (level 1), student interactions with human and non-human resources in the learning environment (level 2), and student interaction with pedagogy or e-learning strategy (level 3). Furthermore, Chou, Peng, and Chang [15] also define interaction in online learning to be the student-self, student-student, student-teacher, student-content, and student interface. The more common types of interactions in online learning are stated by Gradel and Edson [16] which consists of student-content, student-teacher, and student-student interaction. Student-tool interaction is also classified in studentinteraction as non- human [14], [17].

Concept mapping: A student should not only passively receive information or knowledge but they must play an active role in constructing their understanding so that the learning process is also defined as a generative activity [18]. Generative learning is more focused on finding relationships to build new knowledge than just storing information in the short term (working memory) or long term memory. Thus, in generative learning, understanding is a result of the process of building relationships between one concept and another with the initial knowledge, learning experiences and new information [13].

According to Fiorella and Mayer [13], there are eight ways to promote generative learning, including learning by mapping. The concept map is an example of part of learning by mapping, where students convert their understanding into a spatial arrangement of words and make connections between these words. Joseph Novak and his team coined the concept mapping method in the early 1970s. The Theory of Ausable, a meaningful learning theory underpinned the concept mapping theory. A concept map is a way of representing or organizing knowledge. Concept maps identify the way we think, and the way we see relationships between knowledge [19]. Novak [20] implies that CM is a method for enhancing conceptual understanding.

\subsection{Learning analytics in Learning Management System (LMS)}

Currently, popular LMS provides essential tools that allow interactive activities in the course, such as forums, messages, online forms of assignments, virtual classroom, etc. These tools also assist teachers in tracking and monitoring the student learning process, such as status submitted assignment reports, the frequency of access statistics, activity logs on the system.

Online learning in higher education is growing dramatically around the globe. With the asynchronous and synchronous interaction and communication facilities in an online learning environment to substitute the traditional classroom approach, this is 
what makes online learning a part of higher education. The implementation of Learning Analytics can enhance the quality of an online learning process and outcomes due to the fact that it would provide a better understanding of students' performance during the learning process through seeing their learning track records [21].

LA is a sophisticated tool used to enhance learning and education. Interestingly, LA emerged from several fields of science and previous research such as educational data mining, web analytics, business intelligence, as well as academic analytics [22]. LA provides important information to teachers by combining and analyzing students' learning historical data then taking action to reflect and intervene in learning to increase students' absorption of material and participation [23].

Data sources in LA can be in the form of demographic data, online activities, assessments and learning achievement data. All data can be visualized in a variety of ways. The data are presented to the teachers and students. Clow [24] states that interventions and predictions also vary between teachers and students. They would be taking action based on presented LA, for instance, students would compare their learning progress and achievement to other peers, and the teacher would contact identified students who require some additional assistance.

\section{$3 \quad$ Research Design}

\subsection{Participants}

Participants of this research were 53 students who enrolled in the Web Programming Course. They were the third-year students of the Educational Technology Department of Faculty of Education, State University of Malang, Indonesia.

\subsection{Learning procedure}

The research was conducted for 6 weeks with details as follows: 1) Week 1, there were tutorials for all participants in terms of building understanding related to concept mapping that was held in face to face mode (traditional classroom; 2) Week 2, a pretest was conducted to determine the students' initial abilities; 3) Week 3-6, Online learning process which ended up with a posttest to measure learning outcomes.

The learning contents used in this research were the introduction of the Web Programming course, which is related to conceptual knowledge. The LMS was used to present the online learning course equipped with a generative activity feature, namely concept mapping (CM). The CM was built using the jsmind javascript library [25]. Research participants registered to LMS by creating a user identity (user-id) for each student. Student CM results were stored in the LMS system, so students could re-access or re-create them and the teacher could also assess the CM results of each student. 


\subsection{Data collection}

Learning analytics data were taken from two tables in the LMS database system, namely the login table that records information about student login activities and the time duration they spent when using the LMS system. The other table was the session table that records every process of student activity when they accessed the LMS with the user ID and activity ID.

After deleting activity data from the teacher and administrator, the data were filtered on both tables so that the students' activities were obtained. The following are students' activity data consisting of:

- The number of logins: $\mathrm{n} 1=1.139$

- The number of minutes of interaction: $\mathrm{n} 2=22.226$

- The number of interactions record: 8.852 , with details:

- Reading content activity: $\mathrm{n} 3=4.733$

- Working on exercises by building concept mapping activity: $\mathrm{n} 4=2.715$

- Submitting tasks activity n5: 1.404

The post-test consisted of 25 questions that were validated by experts in the field of information technology and educational technology.

\subsection{Data analysis}

Statistical analysis in this study used SPSS version 26 application software. Multiple linear regression (MLR) was used to find relationships between several online learning activities which were categorized as non-human interactions with learning outcomes.. In the context of this study, the independent variable was the number of interactions of each type of interaction listed in Table 2, namely the number of logins, the duration of the logins, the duration of reading the content, the number of interactions in building the $\mathrm{CM}$ (working on exercises using $\mathrm{CM}$ ), as well as number of submitting assignments whereas the dependent variable was the learning outcome, represented by the final grade (posttest) achieved by each student. The MLR method was used to calculate the variance of the dependent variable as a linear combination of the independent variables. Previously, a correlation test was performed to determine the correlation coefficient of each variable. This made it possible to create predictive models for dependent variables based on data from independent variables.

\section{Experimental Research}

\subsection{Students' activities in online learning}

Online learning activities are applied more to individual learning, namely reading content, working on exercises such as using another tool or feature, and submitting 
assignments. These three activities are standard activities carried out by a student in online learning. In this research, working on exercises by constructing concept mapping was chosen by using specific features as a student to non-human interaction.

This research used all data records from Table 1 and Table 2 to record all learning activities. In each table, a different query was carried out using the SQL language which is commonly used to filter data in the MySQL relational database.

Table 1. Query results in table login

\begin{tabular}{|c|c|c|}
\hline user_id & login_count & session_duration \\
\hline 35 & 46 & 450 \\
\hline 36 & 78 & 601 \\
\hline 37 & 63 & 532 \\
\hline 38 & 59 & 485 \\
\hline
\end{tabular}

Table 1 shows login_count column representing the number of student authentication into the LMS and the session_duration column is considered one cycle of user activity that starts when a user connects to the service. These variables and the activities explained the learning behaviour of the online learning students.

Table 2. Query results in table activity

\begin{tabular}{|c|l|c|}
\hline user_id & \multicolumn{1}{|c|}{ Activity } & Count \\
\hline 35 & Reading Contents & 250 \\
\hline 35 & Working on Exercises (Concept Mapping) & 312 \\
\hline 35 & Submitting Assignments & 132 \\
\hline 36 & Reading Contents & 451 \\
\hline 36 & Working on Exercises (Concept Mapping) & 247 \\
\hline 36 & Submitting Assignments & 128 \\
\hline 37 & Reading Contents & 213 \\
\hline 37 & Working on Exercises (Concept Mapping) & 411 \\
\hline 37 & Submitting Assignments & 117 \\
\hline
\end{tabular}

\subsection{Predicting students' learning outcome}

The correlation between two variables had been calculated by using the Spearman Correlation. It was chosen due to some data not being homogeneous and normal, Therefore this non-parametric test was performed. 
Table 3. Spearman Correlation

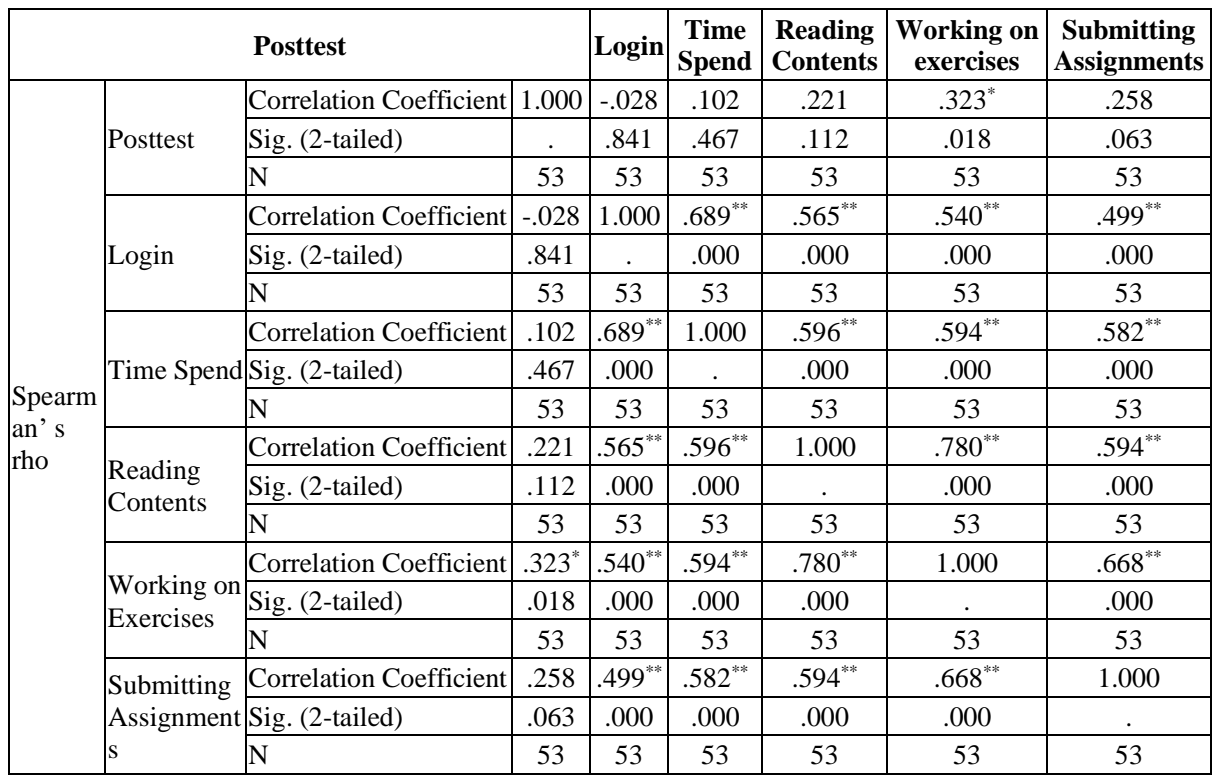

*. Correlation is significant at the 0.05 level (2-tailed)

**. Correlation is significant at the 0.01 level (2-tailed).

Table 3 shows the number of logins was closely related to all activities on the LMS with a $99 \%$ confidence level, however the number of logins was not related to the learning outcomes. Likewise, with the time spent by students in accessing LMS, the Spearman correlation test results showed that the time in accessing LMS was closely related to all variables tested except for the learning outcomes variables.

To interpret the MLR measurement results, several analysis of the test results were conducted including the $\mathrm{F}$ test, T-test, measurement of the coefficient of determination, as well as the multicollinearity test. The following is an explanation regarding the results of several tests that had been carried out.

Table 4. F Test Results

\begin{tabular}{|c|l|c|c|c|c|c|}
\hline \multicolumn{2}{|c|}{ Model } & Sum of Squares & Df & Mean Square & F & Sig. \\
\hline \multirow{3}{*}{1} & Regression & 3202.369 & 5 & 640.474 & 2.991 & $.020^{\mathrm{b}}$ \\
\cline { 2 - 8 } & Residual & 10064.650 & 47 & 214.141 & & \\
\cline { 2 - 7 } & Total & 13267.019 & 52 & & & \\
\hline
\end{tabular}

a. Dependent Variable: Posttest

b. Predictors: (Constant), Submitting Assignment, Reading Contents, Login, Time Spend, Working on Exercises

Based on the F test as shown in Table 4, the error rate or sig. of $0.002<0.005$ was obtained and the value of Fount was greater than Ftable 2.41. So from these results it was concluded that the independent variable simultaneously affected the dependent variable. 
After obtaining the $\mathrm{F}$ value, the results of the determination coefficient measurement was showed (see Table 5). Table 5 shows the $\mathrm{R}$ square value of 0.241 $(24.1 \%)$ and an adjusted $\mathrm{R}$ square of $0.161(16.1 \%)$. Due to more than two independent variables was used, the adjusted $\mathrm{R}$ Square was selected as a reference as the coefficient of determination. This coefficient showed how much the percentage of variation in the independent variable used in the model was able to explain the variation in the dependent variable.

Table 5. Determination coefficient test Result

\begin{tabular}{|c|c|c|c|c|}
\hline Model & R & R Square & Adjusted R Square & Std. Error of the Estimate \\
\hline 1 & $.491^{\mathrm{a}}$ & .241 & .161 & 14.634 \\
\hline
\end{tabular}

a. Predictors: (Constant), Submit Assignment, Read Content, Login, Time Spend, Work Assignment

Next, the multicollinearity measurement was intended to determine whether the regression model used had a strong correlation between independent variables by looking at the tolerance (T) and variance inflating factor (VIF) values. Table 6 shows that the $\mathrm{T}$ value for all independent variables had a value of $>0.1$ and the VIF value for all independent variables had a value of $<10$. So it can be concluded that there was no multicollinearity in this regression model.

Table 6. Multicollinearity assessment result

\begin{tabular}{|c|c|c|}
\hline \multirow{2}{*}{ Independent Variables } & \multicolumn{2}{|c|}{ Collinearity Statistics } \\
\hline & Tolerance & VIF \\
\hline \multicolumn{3}{|l|}{ (Constant) } \\
\hline Login & .610 & 1.640 \\
\hline Time Spend & .575 & 1.739 \\
\hline Reading Contents & .627 & 1.596 \\
\hline Working on Assignments & .445 & 2.245 \\
\hline Submitting Assignments & .553 & 1.807 \\
\hline
\end{tabular}

Table 7 is a summary of the results of the MLR analysis that had been conducted. If the value was Sig. $<0.05$ from an independent variable, it could be concluded that the independent variable had a partial effect on the dependent variable. In addition, by looking at the $t$ value of each independent variable, if the $t$ value $>$ the $t$-table (2.01174), it could be concluded that the independent variable affected partially (individually) on the dependent variable. Table 7 shows that only the variable of working on exercises by using concept mapping had an effect on learning outcomes (post-test). 
Table 7. Multiple linear regression summary

\begin{tabular}{|l|c|c|c|}
\hline \multicolumn{1}{|c|}{ Independent Variables } & Regression Coefficient & T & Sig. \\
\hline (Constant) & 47.572 & 8.840 & .000 \\
\hline Login & -.315 & -1.827 & .074 \\
\hline Time Spend & -.006 & -.479 & .634 \\
\hline Reading Contents & .010 & .277 & .783 \\
\hline Working on Exercises (Concept Mapping) & .303 & 2.325 & .024 \\
\hline Submitting Assignment & .257 & 1.311 & .196 \\
\hline
\end{tabular}

\section{Discussion}

LA is also very likely to be used by anyone who is involved and has an interest in implementing the learning process. Ifenthaler and Widanapathirana [26] divided the levels of stakeholders who might be involved and interested in LA into several levels, namely: mega-level, macro-level, meso-level, and micro-level. Greller and Drachsler [9] emphasize that the application of LA can be used by different stakeholders such as students, teachers, intelligent tutoring systems, educational institutions, researchers, and instructional designers.

Both students and teachers might be concerned about how the analysis of LA can improve the learning quality. How the students' grades will be improved or how teachers are helped to adjust a learning strategy, suitable learning materials based on students' need and their personalities to improve. LA as an analytical tool is utilized by stakeholders in this case educational institutions to support policy making by identifying student' $\mathrm{s}$ failures or learning needs in online learning. According to Campbell, DeBlois, and Diana [27], the learning analytics process is an iterative process consisting of five steps, namely capture, report, predict, act, and refine.

This paper is focused on the third step of the learning analytics process, namely predict step. The analyzed data consisted of students' information about their learning process such as activities of reading contents, working on exercises using $\mathrm{CM}$, submitting assignments, the number of logins, and the amount of time spent in online learning, as well as students' learning outcome. The content presented in this experiment is related to conceptual knowledge so that it requires deeper learning like an application used in learning [28].

From Table 7, this research findings confirmed that doing exercises using CM is the activity that influences the learning outcome. This finding is emphasized by Patrick' s work [29], where he concludes that concept mapping can affect student achievement. Other research findings also agree that the usage of concept mapping in teaching enables the students to achieve higher scores rather than students who are taught by conventional methods [30] [31]. The same is when Computer-Based Concept Mapping (CBCM) is applied in a digital learning environment. CBCM can provide meaningful learning for students [32]. This proves that CM can assist students to understand the concept through the process of constructing knowledge structures.

Moreover, the experiment conducted by Hwang, Yang, and Wang [33] on gamebased learning utilizing $\mathrm{CM}$ found that $\mathrm{CM}$ can significantly improve student learning 
achievement and reduce their cognitive load. Similarly, the results of a recent experiment found that $\mathrm{CM}$ used as a formative assessment can improve Student Engagement and learning outcomes in online learning when compared to using conventional assessments [34]. From the results of their study, it was found that the quantity of reading on LMS was not able to predict the learning outcomes of students. The study of Huang, Chern, and Lin [35] have emphasized these research findings. Huang et al. [35] state that reading activities in online learning can improve learning outcomes but are unable to predict learning outcomes, due to students finding difficulties in understanding the topics in an article that require a complex level of understanding. Huang et al. [35] imply that a special strategy should be needed to help students find ideas from an article and as a result of their study was that CM can help the students to learn.

Concept mapping is one of the generative learning activities where this activity views learning as an act of construction. Everyone understands something by integrating new experiences with their existing knowledge structures [36]. argues that students generate perceptions and meanings that are consistent with their prior knowledge. Besides, the concept map can be used as a tool in developing reflective thinking abilities of students, namely to integrate small pieces of knowledge into a complete and elaborate knowledge structure [37].

Meanwhile, the number of logins was found to correlate with the duration of interaction with the LMS in accessing learning contents, as well as the other independent variables which had a significant correlation between them. Research conducted by Asterhan and Hever [38] also indicate that reading content has a positive effect on learning outcomes. Nevertheless, the amount of interaction in building $\mathrm{CM}$ had a more significant correlation with learning outcomes. These findings were confirmed by the study of You [39] that identifies several interactions in the learning process that can predict learning outcomes. You [39] states that the quantity of interaction with LMS does not necessarily improve learning outcomes but the quality of learning behavior can predict learning outcomes.

In this study, only a few learning activities were included in the non-human interaction category [14], as a result the adjusted $\mathrm{R}$ square value which obtained during the experiment (see section 4) tends to be low. This is because many factors that influence the improvement of learning outcomes in online learning settings [28] which were no measured in this research such as learning motivation [40], studentteacher interaction [41], interactions between students [42], and so on. In addition, according to Ismail, et al. [43] There are four factors that influence student academic performance, namely the use of technology, the interaction process, the characteristics of the student and the characteristics of the class.

Other than that, There have been many studies propose solutions to make interactive activities effectively support the learning process of students. Evans and Sabry [44] implemented three interactive activities: The pace control, self-assessment, interactive simulation of his research and time of using the system is a factor affecting student results. The results of their study showed that students with better results and need less time learning when interacting more with the system. Similarly, according to research findings of Damianov et al. [45], there is a positive influence in the 
duration of time spent online and the results calculated by the scores of students, especially students in the group above average. Contrary to the judgment of Eom et al. [46] showed that there was no relationship between other forms of interaction to the learning outcomes of students. Early research discovered that interactive activities online in the blended learning course have an impact on student learning outcomes.

\section{Conclusion}

The number of online learning users increases which affects the need for an LMS increases. LMS has the advantage of managing online learning by adopting traditional classrooms. Apart from managing, the LMS records all activities of the teachers and students in a feature activity logs. Generated data from this LMS is known as LA. Currently, this LA feature is very important, because data on students' online activities can be interpreted and used to solve problems in learning and assess the effectiveness of online learning.

This study uses LA for specific online learning activities in reading content, working on exercises using CM, submitting assignments, number of logins, login duration (time spent learning online). The purpose of this study is to predict which of these online learning activities will affect the learning outcome. The results of data analysis specifically found the number of logins was closely related to all activities on the LMS with a $99 \%$ confidence level.

However, the number of logins was not related to learning outcomes. Similarly, the time spent by students in accessing LMS, the Spearman correlation test results, showed duration in accessing LMS was closely related to all variables tested except for the learning outcomes variable.

Based on the results of the T-test analysis in the MLR analysis, it was found that only activities working on exercises using $\mathrm{CM}$ affected on learning outcomes with a sig. value of 0.024 , while other activities have a sig value. above 0.05 . These results prove that compared to the activities tested, the use of CM in training is effective in helping students learn content which is related to conceptual knowledge.

\section{$7 \quad$ References}

[1] Y. Ghilay, "Effectiveness of Learning Management Systems in Higher Education: Views of Lecturers with Different Levels of Activity in LMSs," Journal of Online Higher Education, vol. 3, no. 2, pp. 29-50, 2019. http://ojs.iucdt.com/index.php/JOHE/article/vie w/91.

[2] L. -K. Lee, S. K. S. Cheung and L. -F. Kwok, "Learning Analytics: Current Trends and Innovative Practices," Journal of Computers in Education, vol. 7, pp. 1-6, 2020. https://doi. org/10.1007/s40692-020-00155-8.

[3] W. Rayens and A. Ellis, "Creating a Student-Centered Learning Environment Online," Journal of Statistics Education, vol. 26, no. 2, pp. 92-102, 2018. https://doi.org/10.1080/10 691898.2018.1475205.

[4] A. P. Lopes, "Learning Management System in Higher Education," in Proceedings of Edulearn14 Conference, Barcelona, Spain, 2014. 
[5] V. Reischl and J. T. M. Toro, "Learning Management System," in Igniting Your Teaching with Educational Technology, CA, Innovate Learning, 2017, pp. 13-22.

[6] H. Aldowah, H. Al-Samarraie and M. W. Fauzy, "Educational Data Mining and Learning Analytics for 21st Century Higher Education: A Review and Synthesis," Telematics and Informatics, vol 37, pp. 13-49, 2019. https://doi.org/10.1016/j.tele.2019.01.007.

[7] H. V. Jagadish, J. Gehrke, A. Labrinidis, Y. Papakonstantinou, J. M. Patel, R. Ramakrishnan and C. Sahabi, "Big Data and Its Challenge," Communication of The ACM, vol 7, no.7, pp. 86-94, 2014. https://doi.org/10.1145/2611567.

[8] Z. K. Papamitsiou and A. A. Economides, "Learning Analytics and Educational Data Mining in Practice: A Systematic Literature Review of Empirical Evidence," Educational Technology \& Society, vol.17, no.4, pp. 49-64, 2014. https://doi.org/10.2307/jeductech soci.17.4.49.

[9] W. Greller and H. Drachsler, "Translating Learning into Numbers: A Generic Framework for Learning Analytics," Educational Technology \& Society, vol. 15, no. 42, pp. 42-57, 2012. Available at http://citeseerx.ist.psu.edu/viewdoc/download?doi=10.1.1.298.9190\& rep=rep1\&type=pdf.

[10] O. Lu, J. Huang, A. Huang and S. Yang, “Applying learning analytics for improving students engagement and learning outcomes in an MOOCs enabled collaborative programming course," Interactive Learning Environments, vol. 25 ,no.2, pp. 1-15, 2017. https://doi.org/10.1080/10494820.2016.1278391.

[11] T. D. Zimmerman, "Exploring Learner to Content Interaction as a Success Factor in Online Courses," International Review of Research in Open and Distance Learning, vol. 13, no. 4, pp. 152-165, 2012. https://doi.org/10.19173/irrodl.v13i4.1302.

[12] J. C. Tanis, "The seven principles of online learning: Feedback from faculty and alumni on its importance for teaching and learning," Research in Learning Technology, vol. 28, 2020. https://doi.org/10.25304/rlt.v28.2319.

[13] L. Fiorella and R. E. Mayer, Learning as a generative activity, Cambridge University Press, 2015.

[14] A. Hirumi, "A Framework for Analyzing, Designing and Sequencing Planned eLearning Interactions," Quarterly Review of Distance Education, vol 3, no.2, pp. 141-160, 2002.

[15] C. Chou, H. Y. Peng and C. Y. Chang, "The technical framework of interactive functions for course-management systems: students' perceptions, uses, and evaluations," Computers \& Education, vol. 55, no. 3, pp. 1004-1017, 2010. https://doi.org/10.1016/j.compedu.2010. 04.011.

[16] K. Gradel and A. Edson, "Cooperative learning: Smart pedagogy and Tools for Online and Hybrid Course," Journal of Educational Technology System, vol. 39, no. 2, pp. 193-212, 2010. https://doi.org/10.2190/et.39.2.i.

[17] L. Salmi, "Student Experiences on Interaction in an Online Learning Environment as a Part of Blended Learning Implementation: What is Essential," IADIS International Conference e-Learning, pp. 356-360, 2013.

[18] M. Wittrock, "Learning as a Generative Process," Educational Psycchologist, vol. 37, no. 1, pp. 35-46, 1974. https://doi.org/10.1080/00461520903433554.

[19] J. D. Novak and D. W. Gowin, Learning How to Learn, New York and Cambridge: UK: Cambridge University Press, 1984.

[20] J. D. Novak, "Concept maps and Vee diagrams: Two metacognitive tools for science and mathematics education," Instructional Science, vol. 19, pp. 29-52, 1990. https://doi.org/10. 1007/BF00377984.

[21] C. Schumacher and D. Ifenthaler, "The importance of students' motivational dispositions for designing learning analytics," Journal of Computing in Higher Education, vol. 30, no. 3, 2018. https://doi.org/10.1007/s12528-018-9188-y.

[22] T. Elias, "Learning Analytics: Defenition, Process, and Potential," 2011. Available at http ://citeseerx.ist.psu.edu/viewdoc/download?doi=10.1.1.456.7092\&rep=rep1\&type=pdf. 
[23] O. H.-T. Lu, A. Y. Q. Huang, A. J. Q. Lin, H. Ogata and S. J. H. Yang, “Applying Learning Analytics for The Early prediction of Student Academic Performance in Blended learning," Educational Technology and Society, vol. 21, no. 2, pp. 220-232, 2018. from http://www.jstor.org/stable/26388400.

[24] D. Clow, "An overview of learning analytics," Teaching in Higher Education, vol. 18, no. 6, pp. 683-695, 2013. https://doi.org/10.1080/13562517.2013.827653.

[25] Z. Zhang, "Js MIND," 2015. [Online]. Available: https://github.com/hizzgdev/jsmind.

[26] D. Ifenthaler and C. Widanapathirana, "Development and Validation of a Learning Analytics Framework: Two Case Studies Using Support Vector Machines," Technology, Knowledge and Learning, vol.19, no.(1-2), p. 221-240, 2014. https://doi.org/10.1007/s10 758-014-9226-4

[27] J. P. Campbell, P. B. DeBlois and G. Diana , "Academic Analytics: A New Tool for a New Era," Educause Review, vol. 42, no. 4, p. 40-57, 2007.

[28] H. Kauffman, "A Review of Predictive Factors of Student Success in and Satisfaction with Online Learning," Research in Learning Technology, vol. 23, 2015. https://doi.org/10.34 02/rlt.v23.26507.

[29] A. O. Patrick, "Concept Mapping As a Study Skill: Effects on Students Achievement in Biology," International Journal of Education Science, vol. 3, no. 1, pp. 49-57, 2011. https ://doi.org/10.1080/09751122.2011.11890008.

[30] A. B. Cheema and M. S. Mirza, "Effect of Concept Mapping On Students' Academic Achievement, vol. 7, no.2," Journal of Research \& Reflections in Education , 2013.

[31] E. Otor, "Effect of Concept Mapping Strategy on Students' Achievement in Difficult Chemistry Concepts in Rural and Urban Areas in Benue State, Nigeria," International Journal of Case Studies, vol. 2, no. 8, 2013. Available at SSRN: https://ssrn.com/abstract= 2868349 .

[32] G. Aşıksoy, "Computer-based concept mapping as a method for enhancing the effectiveness of concept learning in technology-enhanced learning," Sustainability, vol. 11, no. 4, 2019. https://doi.org/10.3390/su11041005.

[33] G. J. Hwang, L. H. Yang and S. Y. Wang, "A concept map-embedded educational computer game for improving students' learning performance in natural science courses," Computers and Education, vol. 69, no. 1, p. 121-130, 2013. https://doi.org/10.1016/j.comp edu.2013.07.008.

[34] I. Fatawi, I. N. S. Degeng, P. Setyosari and S. Ulfa, "Effect of Online-based Concept map on Student Engagement and Learning Outcome," International Journal of Distance Education Technologies , vol. 18, no. 3, 2020. https://doi.org/10.4018/ijdet.2020070103.

[35] H. Huang, C. Chern and C. Lin, "EFL students' use of online reading strategies and comprehension of texts: An exploratory study," Computers \& Education, vol. 25, no. 1, pp. 13-26, 2009. https://doi.org/10.1016/j.compedu.2008.06.003.

[36] F. C. Bartlet, Remembering: A study in experimental and social psychology, Cambridge, UK: Cambridge University Press, 1932.

[37] A. Collins and J. S. Brown, "The computer as a tool for learning through reflection," in Learning Issues for Intelligent Tutoring System, Springer-Verlag, 1988. https://doi.org/10. 1007/978-1-4684-6350-7_1,pp.1-18.

[38] C. Asterhan and R. Hever, "Learning from Reading Argumentive Group Discussions in Facebook: Rhetoric Style Matters (again)," Computers in Human Behavior, vol. 53, pp. 570-576, 2015. https://doi.org/10.1016/j.chb.2015.05.020.

[39] J. W. You, "Identifying significant indicators using LMS data to predict course achievement in online learning," The Internet and Higher Education, vol. 29, pp. 23-30, 2016. https://doi.org/10.1016/j.iheduc.2015.11.003.

[40] M. -H. Lin, H. -C. Chen and K. -S. Liu, "A Study of the Effects of Digital Learning on Learning Motivation and Learning Outcome," EURASIA Journal of Mathematics Science 
and Technology Education, vol. 13, no. 7, pp. 3553-3564, 2017. https://doi.org/10.12973/ eurasia.2017.00744a.

[41] J. Moore, "Effects of Online Interaction and Instructor Presence on Students' Satisfaction and Success with Online Undergraduate Public Relations Courses," Journalism \& Mass Communication Educator, vol. 69, no. 3, pp. 271-288, 2014. https://doi.org/10.1177/1077 695814536398.

[42] S. -P. Yeh and H. -W. Fu, "Effects of Cooperative E-Learning on Learning Outcomes," Eurasia Journal of Mathematics, Science \& Technology Education, vol. 10, no. 6, pp. 531536, 2014. https://doi.org/10.12973/eurasia.2014.1212a.

[43] A. O. Ismail, A. K. Mahmood and A. Abdelmaboud, "Factors Influencing Academic Performance of Students in Blended and Traditional Domains," International Journal of Emerging Technologies in Learning, vol. 13, no. 2, pp. 170-187, 2018. https://doi.org/10. 3991/ijet.v13i02.8031.

[44] C. Evans and K. Sabry, "Evaluation of the interactivity of Web-based learning systems: Principles and process," Innovations in Education and Teaching International, vol 40, no.1, vol. 40, no. 1, pp. 89-99, 2003. https://doi.org/10.1080/1355800032000038787.

[45] D. S. Damianov, L. Kupczynski, P. Calafiore, E. Damianova, G. Soydemir and E. Gonzalez, "Time Spent Online and Student Performance in Online Business Courses: A Multinomial Logit Analysis," Journal of Economics and Finance Education, vol. 8, no. 2, 2009. Available at https://www.economics-finance.org/jefe/issues/JEFE-Vol-8-Num-2-Wi nter-2009.pdf.

[46] S. Eom, J. Wen and N. J. Ashill, "The Determinants of Students' Perceived Learning Outcomes and Satisfaction in University Online Education: An Empirical Investigation," Decision Sciences Journal of Innovative Education, vol. 42, no. 2, pp. 215-235, 2006. https://doi.org/10.1111/j.1540-4609.2006.00114.x.

\section{Authors}

Saida Ulfa is a lecturer of Educational Technology Department, Faculty of Education, State University of Malang, Indonesia. She is also a member of Center of Excellence PUI-PT Disruptive Learning Innovation, State University of Malang. She received her Master of Education and Doctor of Philosophy from Saga University Japan in 2005 and 2009, respectively.

Izzul Fatawi is a lecturer of Tarbiyah Department, Faculty of Education, Islamic Institute of Nurul Hakim, Lombok, Indonesia. He received his Master of Education from UIN Sunan Ampel Surabaya in 2011 and completed his doctoral degree in 2020 from Educational Technology Department, Faculty of Education, State University of Malang, Indonesia. Currently, he is a vice rector for academic affairs at Islamic State Institute of Nurul Hakim, Lombok, Indonesia.

Article submitted 2020-06-15. Resubmitted 2020-09-10. Final acceptance 2020-09-11. Final version published as submitted by the authors. 